\title{
Laboreal
}

Volume $13 \mathrm{~N}^{\circ} 1$ | 2017

Varia

\section{¿Qué es una aptitud profesional?}

o que é uma aptidão profissional?

Qu'est-ce qu'une aptitude professionnelle?

What is an occupational skill?

\section{Jean-Maurice Lahy}

Traductor. Cecilia De la Garza y Mario Poy

\section{OpenEdition}

\section{Journals}

Edición electrónica

URL: http://journals.openedition.org/laboreal/2010

DOI: 10.4000/laboreal.2010

ISSN: 1646-5237

Editor

Universidade do Porto

\section{Referencia electrónica}

Jean-Maurice Lahy, « ¿Qué es una aptitud profesional? », Laboreal [En línea], Volume 13 Nº 1 | 2017

Publicado el 01 julio 2017, consultado el 24 septiembre 2020. URL : http://journals.openedition.org/ laboreal/2010 ; DOI : https://doi.org/10.4000/laboreal.2010

Este documento fue generado automáticamente el 24 septiembre 2020.

\section{c) (i) (8)}

Laboreal está licenciado com uma Licença Creative Commons - Atribuição-NãoComercial 4.0 Internacional. 


\title{
¿Qué es una aptitud profesional?
}

\author{
o que é uma aptidão profissional? \\ Qu'est-ce qu'une aptitude professionnelle? \\ What is an occupational skill?
}

Jean-Maurice Lahy

Tradución : Cecilia De la Garza y Mario Poy

\section{REFERENCIA}

Artigo original: Lahy, J.-M. (1922). Qu'est-ce qu'une aptitude professionnelle ? III ${ }^{\mathrm{e}}$ conférence internationale de psychotechnique appliquée à l'orientation professionnelle, Milan, 24 octobre 1922, Atti della III ${ }^{\text {e }}$ conferve internazionale de psicotecnica applicata al orientamento profesionale, Milan, Società umanitaria.

1 La idea de proceder a la orientación profesional de la juventud ha vencido hoy en día toda resistencia. Es aceptado el hecho que no se puede dejar al azar la selección de las profesiones sino que, al contrario, se lo debe substituir por una determinación racional de las carreras en las que los jóvenes deben encaminarse.

2 Sin embargo, a pesar de esa unanimidad de las opiniones, dicha cuestión no progresa. $\mathrm{Al}$ especular sobre el concepto de "orientación profesional", muchos quieren aprovechar del movimiento de opinión creado para repartir la mano de obra juvenil, en favor de ciertas industrias. Es decir que preocupándose solo de la demanda del mercado local, no se ofrece a los jóvenes las profesiones en las que podrían tener éxito, sino aquellas para las cuales la mano de obra es requerida.

Digamos ante todo, que en nuestra opinión, esos dos intereses: el interés del futuro aprendiz y el interés de los empleadores, no deberían oponerse sino conjugarse. En efecto, si la orientación profesional está bien hecha, debe entonces haber un reclutamiento de trabajadores de elite para cada profesión y proveer un empleo a cada trabajador. Considerar el problema únicamente desde un solo punto de vista llevará inevitablemente a un fracaso y se descreditará la orientación profesional sin lograr 
cambiar nada -ni desde el punto de vista social, ni desde el punto de vista individualrespecto del orden existente de las cosas.

4 Pensamos que esa divergencia de opiniones obedece, más que de una hostilidad de parte de la empresa, a una falta de claridad en cuanto a la manera de plantear el problema.

5 En efecto algunas organizaciones dirigen de manera inadecuada la orientación profesional hacia la simple repartición de la mano de obra de los jóvenes, grupos industriales y de comerciantes se han puesto en contacto con los psico-fisiólogos y profesores informados, ya que entienden el interés que representa la orientación profesional fundada en bases científicas.

6 Que se nos permita citar, entre las tentativas más exitosas, la de la "Escuela en el taller". Su comité, formado de miembros de la enseñanza y de la industria, que apoyan financieramente la creación de un oficio de orientación profesional, estima que la identificación de las aptitudes de los niños debe efectuarse de manera paralela a aquella de la condiciones del mercado de trabajo.

7 De hecho, los partidarios de las dos tesis -orientación profesional y repartición de mano de obra de los jóvenes- concuerdan con el hecho de que las aptitudes de los niños deben ser tomadas en consideración. Pero, mientras que los primeros tienen una noción precisa del problema, para los segundos se concretiza en una simple formulación verbal que no conlleva a ninguna modificación en la práctica.

8 Es importante por tanto, si se quiere plantear ante todo el problema de la orientación profesional a partir de datos verdaderos, definir lo que se entiende por "aptitudes".

9 Además de su sentido general, la palabra aptitud puede ser aplicada a casos particulares: solo conservamos aquel que significa "disposición natural para...". Para nosotros una aptitud será una disposición natural para ejercer convenientemente un oficio. Pero ¿qué es una disposición natural? Creemos que es una disposición orgánica que puede ser constatada ya sea anatómicamente, ya sea fisiológicamente, ya sea psicológicamente. Es así como una estatura de 1,60m o un peso de 40 kilos constituyen disposiciones naturales: una para ser soldado, la otra para ser jockey. Una buena capacidad y un alto índice pulmonar serán disposiciones naturales de un individuo para ejercer oficios que impliquen trabajar en ambientes confinados, o con materias tóxicas. Para oficios que exijan fuerza muscular, es necesario poseer, además de una capacidad muscular importante, órganos de eliminación de las toxinas que funcionen bien. En fin, mediante la aplicación de tests psicológicos o psico-motores se determinan las disposiciones naturales de los aprendices para ejercer profesiones más complejas.

10 La investigación de las disposiciones naturales fue considerada por mucho tiempo imposible en lo que se refiere a las funciones mentales Pero desde que Binet dedicó el final de su vida al estudio objetivo de la inteligencia, la cuestión se precisó introduciéndose la noción de medida.

11 El problema de las disposiciones naturales -que nos va a permitir abordar de manera más segura el de las aptitudes- puede sintetizarse en estos dos puntos de investigación:

$121^{\circ}-i$ Las funciones mentales son independientes las unas de las otras? ¿Podemos, por tanto, al totalizar los resultados de los tests, tener una indicación precisa sobre el valor de un niño para una profesión dada? 
$2^{\circ}$ - ¿O más bien debemos introducir -con esta noción de tests independientes- la idea de una inteligencia general que domina las aptitudes particulares?

Sin entrar en detalles de teorías relativas a la influencia reciproca de las diversas funciones se las puede resumir en dos tesis esenciales:

- La primera es la de Thorndike según la cual la inteligencia está compuesta de facultades yuxtapuestas, pero independientes. La consecuencia de esta concepción de la inteligencia es que un test que mide una aptitud característica no está correlacionada con los tests que miden aptitudes diferentes salvo, tal vez, en algunos casos de semejanza muy estrecha.

- La segunda es la de Spearmann según la cual poseemos, además de las funciones mentales particulares, una inteligencia general capaz de actuar sobre éstas. Esto tiene como consecuencia el llevarnos a creer que los tests que se aplican a funciones semejantes están correlacionados de manera estrecha y permiten conocer el valor de vastos territorios psicológicos homogéneos.

Para juzgar de manera justa estas dos tesis, hay que considerar que dichos autores se situaron desde dos puntos de vista distintos: Thorndike, trabaja sobre los elementos de la inteligencia y Spearmann, sobre los resultados de un complejo.

Ahora bien, lo complejo, como sabemos, no refleja necesariamente las cualidades de sus elementos; es sobre esta noción que se demuestra fácilmente, que se funda la teoría evolucionista de los fenómenos de conciencia.

7 La teoría de Spearmann es por lo tanto más exacta. Sin embargo no se le puede aceptar sin algunas reservas ya que el autor admite que existen correlaciones muy frecuentes y estrechas entre funciones notoriamente diferentes -tales como la discriminación de las sensaciones y la manera de triunfar en la vida.

En lo que se refiere a un hecho nuevo, mientras que Thorndike lo niega, Spearmann lo relaciona fuertemente con los factores elementales que lo originaron. Sin embargo desde un punto de vista práctico -que tenemos que crear para reconocer las aptitudesambos están en un error ya que una función tiene todo su valor para detectar una aptitud solo si se le considera en relación con la inteligencia general. Pero ese vínculo de dependencia no debe ser tan estrecho, ni tan fijo para que se puedan establecer fácilmente las leyes estrictas, tal como lo supone Spearmann. De hecho cabe recordar que existen casos en los cuales la función tiene que ser juzgada de manera aislada, porque no siempre sigue el órgano.

9 Para nosotros se tratara siempre de determinar tanto el valor de la inteligencia general como el de las funciones particulares pues una reacciona sobre las otras. Así, los experimentos realizados en sujetos seleccionados al azar y en estudiantes muestran a menudo una superioridad en las actividades mentales en las personas que no se dedican a la cultivar su cultura, pero cuya inteligencia es superior a la de los especialistas. Es así como, cuando Munsterberg aplicó su test de selección de choferes a los empleados de una empresa de transporte y a estudiantes de la Universidad de Harvard, observó que estos últimos presentaban en la realización del test, una superioridad sobre los primeros. La inteligencia general refuerza entonces, en muchos casos, las actividades particulares. Parece que se produce un tipo de fenómeno de suplencia que facilita la adaptación.

La determinación de las disposiciones naturales debe entonces conducir:

- por un lado sobre las funciones elementales cuyo valor caracteriza la superioridad para una profesión dada y, por otro lado, sobre la inteligencia general del sujeto. 
21 Según nosotros esta definición de las aptitudes nos permite afirmar que son: disposiciones naturales que se reconocen por respuestas motrices o mentales -que se pueden medir- a estímulos definidos. La inteligencia general entra dentro del cuadro de las aptitudes. específicamente- ejercidas por el ser humano. Perece entonces que los seres humanos los más inteligentes pueden ser dirigidos de manera indistinta a tal o cual oficio. En efecto, se observa frecuentemente en la práctica que los sujetos talentosos intelectualmente presentan aptitudes para profesiones diversas, lo que facilita su orientación. Ante ese hecho, se impone una conclusión: con el fin de no obstruir con sujetos de elite las profesiones que exigen un número limitado de aptitudes especiales, el objetivo será de buscar, para los más talentosos, la profesión de orden más elevada en donde podrán tener éxito, es decir aquella que exija, el número más elevado de aptitudes especiales y el máximo de inteligencia. 